\title{
BMJ Open Association of breast feeding with early childhood dental caries: Japanese population-based study
}

\author{
Tsuguhiko Kato, ${ }^{1}$ Takashi Yorifuji, ${ }^{2}$ Michiyo Yamakawa, ${ }^{3}$ Sachiko Inoue, ${ }^{4}$ \\ Keiko Saito, ${ }^{5}$ Hiroyuki Doi, ${ }^{5}$ Ichiro Kawachi ${ }^{6}$
}

To cite: Kato T, Yorifuji T, Yamakawa M, et al. Association of breast feeding with early childhood dental caries: Japanese populationbased study. BMJ Open 2015;5:e006982. doi:10.1136/bmjopen-2014006982

- Prepublication history for this paper is available online. To view these files please visit the journal online (http://dx.doi.org/10.1136/ bmjopen-2014-006982).

Received 22 October 2014 Revised 25 February 2015 Accepted 26 February 2015

CrossMark

For numbered affiliations see end of article.

Correspondence to Dr Tsuguhiko Kato; tsuguhiko.kato@gmail.com

\section{ABSTRACT}

Objectives: We investigated the association between breastfeeding duration during the first half year of life and the risk of early childhood caries from the age of 30 to 66 months in Japan.

Design: Observational study of a longitudinal survey. Setting: A secondary data analysis of the Japanese Longitudinal Survey of Babies in the 21st Century.

Participants: 43383 infants at the age of 6 months.

Outcome measures: Early childhood caries-defined as a child's visit to a dentist for treatment of dental caries during the past 12 months-was ascertained from the caregiver from the age of 30 months in the survey. We estimated the risk of dental caries each year according to duration of breast feeding using logistic regression analyses. We controlled for a set of biological factors (birth weight, sex, parity and maternal age at delivery) and socioeconomic factors (maternal educational attainment and smoking status, marital status at delivery, family income and region of birth and residence).

Results: We found that infants who had been breast fed for at least 6 or 7 months, both exclusively and partially, were at elevated risk of dental caries at the age of 30 months compared with those who had been exclusively formula fed. Adjusted ORs were 1.78 (95\% $\mathrm{Cl}$, (1.45 to 2.17)) for the exclusively breastfed group and 1.39 (1.14 to 1.70$)$ for the partially breastfed group. However, the associations became attenuated through the follow-up period and were no longer statistically significant beyond the age of 42 months for the partially breastfed group and beyond the age of 54 months for the exclusively breastfed group.

Conclusions: We found an association between breast feeding for at least 6 or 7 months and elevated risk of dental caries at age 30 months. However, the association became attenuated as children grew older.

\section{BACKGROUND}

Although the prevalence of dental caries in developed countries such as the USA and Japan has declined over recent decades, ${ }^{1}{ }^{2}$ dental caries remain one of the most common infectious diseases among young

\section{Strengths and limitations of this study}

- Using a longitudinal survey of 43383 children from all over Japan, we estimated the risk of dental visits due to dental caries associated with breastfeeding duration each year from the age of 30 to 66 months. Since socioeconomic status is known to be a strong determinant of early childhood caries, we utilised rich information contained in the survey to control for various socioeconomic factors.

- We did not have information on the frequency or duration of breast feeding within a day. Therefore, further research with methods that precisely measure the daily amount of time spent on breast feeding may be necessary.

- Since our outcome assessment of children's dental caries relied on the caregiver's report of dental visits, the incidence of dental caries in our study may be underestimated.

- Levels of parental compliance with health-related guidelines were not accounted for in the analyses. High compliance may be associated with both adherence to the official guidelines for exclusive breast feeding up to 6 months and willingness to seek preventive dental care for a young child.

children. The microbiological process of dental caries has been well established. ${ }^{3}$ The initiation and progression of caries occur due to the interaction of three factors: oral microorganisms, dietary carbohydrates and tooth enamel. Microorganisms such as Streptococcus mutans colonise the tooth's surface, feed on incoming refined carbohydrates and produce acids which result in demineralisation of the tooth. Continuation of lower $\mathrm{pH}$ and loss of minerals undermine the tooth and cause permanent damage over time.

Organisations such as the WHO, the American Academy of Pediatrics and the Japanese Pediatric Society recommend exclusive breast feeding for at least 6 months 
because of the many benefits that breast feeding provides. ${ }^{4-6}$ However, breast milk contains sugars and may be cariogenic. ${ }^{78}$ Paediatric dentistry organisations such as the American Academy of Pediatric Dentistry and the Japanese Society of Pediatric Dentistry referred to the potential risk of early childhood caries associated with breast feeding in their policy statements. ${ }^{9} 10$

Reviews of epidemiological studies have found the relationship between breast feeding and early childhood caries to be inconclusive. ${ }^{11} 12$ A few studies suggest that breast feeding may promote dental caries, ${ }^{13-15}$ while other studies have not found an association. ${ }^{16-20}$ Therefore, we sought to examine the association of breast feeding during the first half year of life with dental caries between the ages of 30 and 66 months.

\section{METHODS}

Description of the data

The Japanese Ministry of Health, Labour and Welfare (MHLW) has been implementing a survey on children and their parents annually since 2001. The original purpose of this survey, known as the Longitudinal Survey of Babies in the 21st Century (LSB21), was to assist the MHLW in developing strategies to counter the rapidly declining fertility rate in Japan. ${ }^{21}$

The target population was families from all over Japan with a newborn baby (or babies) delivered between 10 and 17 January or July 2001. The baseline questionnaire was sent to all the families when the newborns reached 6 months or 7 months of age. Among the 53575 mailed questionnaires, 47015 were filled and returned $(88 \%$ response rate). Follow-up questionnaires have been sent to these participating families annually (at 18 months, 30 months, 42 months and so on). Birth records from Japanese vital statistics, which include birth length and weight, gestational age, sex, parental age and other information, were also linked to each child in this survey.

\section{Infant feeding}

We obtained information on types and duration of infant feeding from the first survey when the babies were 6 or 7 months old. The first question inquired whether a mother breast fed, formula fed or both. The second question ascertained the duration of breast feeding and formula feeding in months between 0 and 7. On the basis of responses to these two questions, we created the following five groups: an exclusively breastfed group, three partially breastfed groups and an exclusively formula fed group. According to the WHO definition, exclusive breast feeding refers to only breast feeding with no other food or drink, whereas predominant breast feeding refers to mainly breast feeding with some other liquids such as water. ${ }^{4}$ Therefore, the exclusive breastfeeding group in our analyses most likely included those with predominant breast feeding.

Those in the exclusively breastfed group indicated 6 or 7 months of breast feeding and 0 month of formula feeding. Those in the exclusive formula feeding group indicated 0 month of breast feeding and 6 or 7 months of formula feeding. Those who both breast fed and formula fed their babies indicated various durations of breast and formula feeding between 1 and 7 months. Therefore, we categorised partially breastfed infants into three groups based on the duration of breast feeding: 1-2, 3-5 and $6-7$ months. It is highly likely that many of the mothers who had breast fed for 6-7 months at the first survey had continued to breastfeed afterwards, but we could not ascertain the duration information. Therefore, we will hereafter refer to the breast fed for 6-7 months groups as exclusively and partially breast fed for at least 6-7 months. We do not have information on whether these partially breastfed infants had been exclusively breast fed for a certain duration before they were formula fed or the mothers both breast fed and formula fed from the beginning within the duration of breast feeding.

We excluded 246 infants from the analyses because of missing information on the type of feeding and an additional 516 because of missing information on the duration of breast feeding. We also restricted our analyses to singleton babies born full term (ie, 37 gestational weeks or later). After these missing data and restrictions, we retained 43383 at the first survey (92\% of the original sample).

\section{Dental caries}

In each follow-up survey from the third, whether a caregiver reported that the child had a dental visit due to dental caries in the 12 months before the survey date was ascertained (eg, between 18 and 30 months at the third survey and between 30 and 42 months at the fourth survey). The question, "Did your child go to a hospital or a clinic because he or she had experienced the following disease or injury (e.g., measles, influenza, asthma, etc) during the last 12 months?", specified dental visits due to dental caries rather than dental visits due to concerns about caries or other dental issues. We used the response to this question as our outcome of interest. The frequency of dental visits or the number of decayed teeth was not ascertained. The same question was not included in the second survey (ie, dental visits between 6 and 18 months of age).

\section{Covariate selection}

Part of the difficulty in determining whether or not breast feeding promotes early childhood caries is due to confounding-reviews suggest that various biological and social factors are associated with early childhood caries. ${ }^{22} 23$ On the basis of the previous literature and utilising rich information contained in the LSB21, we adjusted for a set of biological and socioeconomic factors as potential confounders. Biological factors include birth weight (continuous), sex (dichotomous), parity (categorical) and maternal age at delivery (categorical). Socioeconomic factors include maternal educational attainment (categorical), maternal smoking status (categorical), marital status at 
delivery (dichotomous), family income (continuous) and region of birth and residence (categorical).

We obtained birth weight, sex, parity, maternal age and marital status at delivery and region of birth and residence from the birth record; maternal smoking status and family income from the first survey; and maternal educational attainment from the second survey. Parity represents the number of births given by a mother and therefore informs the presence or absence of older siblings.

We separated maternal age into four groups: below 25; 25 to below 30; 30 to below 35; and 35 and above. We categorised educational attainment into three levels: completed high school or less, completed 2-year college or vocational school, and completed 4-year college or more. We also categorised smoking status into three levels based on the number of cigarettes smoked per day: non-smokers, light smokers (ie, 1-11 cigarettes per day) and heavy smokers (12 or more cigarettes per day). Marital status indicates that the father and mother were married or not when their baby was born. Family income indicates the combined amount of annual earnings from the father, mother and other sources in 10000 yen (equivalent to roughly US\$100). Though Japan is considered to be much more homogeneous culturally than other countries such as the USA, we included eight regions of Japan where children were born and had resided at the first survey in the model to account for cultural and geographical differences that may affect both breastfeeding practices and incidence of dental caries. On the basis of the location of birth, we categorised each child into one of the following regions: Hokkaido, Tohoku, Kanto, Chubu, Kinki, Chugoku, Shikoku and Kyushu/Okinawa.

\section{Statistical analyses}

We conducted logistic regression analyses to evaluate the relationship between the duration of breast feeding and the risk of dental caries each year from the age of 30 to 66 months. We first estimated the crude OR and 95\% CIs among the five breastfeeding groups and then recalculated the OR and 95\% CI after controlling for potential confounders. The exclusively formula fed group served as the reference group. In addition, we collapsed the breastfeeding categories and made two comparisons: (1) never breast fed (ie, 0 month of breast feeding) versus ever breast fed (ie, 1 or more months of breast feeding) and (2) breast fed for less than 6 months versus breast fed for at least $6-7$ months. We conducted our analyses with complete cases. All the statistical analyses were carried out with Stata (V.12/SE, STATA Corp., Texas, USA).

\section{RESULTS}

\section{Baseline characteristics}

In table 1, we summarise the baseline characteristics of participants in the study by breastfeeding groups. Among the 43383 infants, $54 \%$ were breast fed for at least 6 or 7 months: $22 \%$ were exclusively breast fed and $32 \%$ were partially breast fed. Only $6 \%$ were exclusively formula fed. Those in the exclusively breastfed group were born heavier and with more older siblings on average. Examination of maternal age at delivery and socioeconomic factors demonstrated that those in the exclusively breastfed group and partially breast fed for at least 6-7 months group were nurtured in a more socially endowed environment (eg, higher family income, more educated mothers, non-smoking mothers or mothers older than 25).

\section{Bivariate analyses}

In table 2, we present bivariate analyses of biological and socioeconomic factors with dental caries at each age. Although birth weight and family income were treated as continuous variables in the statistical analyses, we categorised them to illustrate their relationships to dental caries. We observed a gradient by birth weight and parity. The relationship between maternal age at delivery and dental caries drew a $U$ shape. Mothers younger than 25 and older than 35 reported more dental visits than those between 25 and 35 .

Corroborating with study findings from other countries, we observed a gradient by maternal educational attainment. Less educated mothers reported more dental visits due to dental caries compared with more educated mothers. We also observed a gradient by smoking status among mothers or family income. These trends continued from the third to the sixth survey. A Japanese national survey suggests that the occurrence of dental caries among young children varies across regions; dental caries were more prevalent in more rural areas such as Tohoku and Kyushu/Okinawa. ${ }^{24}$ We confirmed higher proportions of children with dental caries in these two regions compared to the Kanto area at the third survey in LSB21.

\section{Risk of dental caries by breastfeeding groups}

In table 3, we present associations between breastfeeding groups and the risk of dental caries at each age from 30 to 66 months. The risk of dental caries at 30 months was higher among groups that had been breast fed for at least 6-7 months, both exclusively and partially breast fed, compared with those who had been exclusively formula fed: adjusted OR with $95 \%$ CIs in brackets, 1.78 (1.45 to 2.17 ) among exclusively breast fed and 1.39 (1.14 to 1.70) among partially breast fed for at least 6-7 months. However, the associations between breast feeding for at least 6-7 months and dental caries waned as children grew older. Though ORs remained elevated, the associations were no longer statistically significant beyond 42 months of age for the partially breast fed for at least 6-7 months group and beyond 54 months for the exclusively breastfed group. The comparison of crude and adjusted ORs indicated that the associations of dental caries with the exclusively breastfed group or partially breastfed group 
Table 1 Baseline characteristics of children by breastfeeding groups in the longitudinal survey of babies in the 21 st century $\left(\mathrm{n}_{\text {baseline }}=43383\right)$

\begin{tabular}{|c|c|c|c|c|c|}
\hline & \multirow{2}{*}{$\begin{array}{l}\text { Exclusively } \\
\text { formula fed } \\
(\mathrm{n}=2597)\end{array}$} & \multicolumn{3}{|c|}{ Partially breast fed } & \multirow{2}{*}{$\begin{array}{l}\text { Exclusively } \\
\text { breast fed } \\
(\mathrm{n}=9521)\end{array}$} \\
\hline & & $\begin{array}{l}1-2 M \\
(n=8592)\end{array}$ & $\begin{array}{l}3-5 M \\
(n=8625)\end{array}$ & $\begin{array}{l}6-7 M \\
(n=14048) \\
\end{array}$ & \\
\hline \multicolumn{6}{|l|}{ Biological factor } \\
\hline Birth weight, g & 3064 & 3059 & 3075 & 3088 & 3111 \\
\hline (SD) & (404) & (388) & (377) & (370) & (361) \\
\hline Female & $47 \%$ & $48 \%$ & $50 \%$ & $47 \%$ & $50 \%$ \\
\hline \multicolumn{6}{|l|}{ Parity } \\
\hline 1 (no older siblings) & $49 \%$ & $49 \%$ & $52 \%$ & $54 \%$ & $41 \%$ \\
\hline 2 & $35 \%$ & $37 \%$ & $35 \%$ & $33 \%$ & $42 \%$ \\
\hline 3 & $12 \%$ & $12 \%$ & $10 \%$ & $10 \%$ & $15 \%$ \\
\hline$\geq 4$ & $4 \%$ & $3 \%$ & $2 \%$ & $2 \%$ & $3 \%$ \\
\hline \multicolumn{6}{|l|}{ Maternal age at delivery } \\
\hline$<25$ & $17 \%$ & $20 \%$ & $16 \%$ & $10 \%$ & $11 \%$ \\
\hline $25.1-29.9$ & $36 \%$ & $39 \%$ & $40 \%$ & $38 \%$ & $39 \%$ \\
\hline $30-34.9$ & $31 \%$ & $30 \%$ & $32 \%$ & $38 \%$ & $39 \%$ \\
\hline$\geq 35$ & $16 \%$ & $11 \%$ & $12 \%$ & $14 \%$ & $12 \%$ \\
\hline \multicolumn{6}{|l|}{ Socioeconomic factor } \\
\hline \multicolumn{6}{|l|}{ Maternal educational attainment* ${ }^{\star}$} \\
\hline High school or less & $63 \%$ & $58 \%$ & $47 \%$ & $37 \%$ & $37 \%$ \\
\hline Two-year college or vocational school & $31 \%$ & $34 \%$ & $41 \%$ & $45 \%$ & $45 \%$ \\
\hline Four-year college or higher & $6 \%$ & $8 \%$ & $12 \%$ & $18 \%$ & $18 \%$ \\
\hline \multicolumn{6}{|l|}{ Maternal smoking status* } \\
\hline Non-smoker & $69 \%$ & $68 \%$ & $79 \%$ & $90 \%$ & $92 \%$ \\
\hline Light smoker & $17 \%$ & $18 \%$ & $14 \%$ & $8 \%$ & $6 \%$ \\
\hline Heavy smoker & $14 \%$ & $14 \%$ & $7 \%$ & $2 \%$ & $2 \%$ \\
\hline \multicolumn{6}{|l|}{ Marital status } \\
\hline Not married & $2 \%$ & $2 \%$ & $1 \%$ & $1 \%$ & $1 \%$ \\
\hline $\begin{array}{l}\text { Family income } \\
\text { In } 10000 \text { yen (SD) }\end{array}$ & $\begin{array}{l}522 \\
(558)\end{array}$ & $\begin{array}{l}511 \\
(318)\end{array}$ & $\begin{array}{l}554 \\
(391)\end{array}$ & $\begin{array}{l}594 \\
(366)\end{array}$ & $\begin{array}{l}576 \\
(353)\end{array}$ \\
\hline \multicolumn{6}{|l|}{ Region of birth } \\
\hline Hokkaido & $4 \%$ & $4 \%$ & $4 \%$ & $3 \%$ & $4 \%$ \\
\hline Tohoku & $12 \%$ & $11 \%$ & $8 \%$ & $6 \%$ & $5 \%$ \\
\hline Kanto & $38 \%$ & $33 \%$ & $33 \%$ & $32 \%$ & $27 \%$ \\
\hline Chubu & $16 \%$ & $17 \%$ & $17 \%$ & $19 \%$ & $19 \%$ \\
\hline Kinki & $14 \%$ & $17 \%$ & $18 \%$ & $19 \%$ & $20 \%$ \\
\hline Chugoku & $4 \%$ & $5 \%$ & $6 \%$ & $6 \%$ & $8 \%$ \\
\hline Shikoku & $4 \%$ & $4 \%$ & $3 \%$ & $2 \%$ & $3 \%$ \\
\hline Kyushu/Okinawa & $9 \%$ & $9 \%$ & $10 \%$ & $13 \%$ & $14 \%$ \\
\hline
\end{tabular}

*There were 3030 missing cases for maternal educational attainment, 281 missing cases for maternal smoking status and 2767 missing cases for family income.

for at least 6-7 months became more pronounced after adjusting for biological and socioeconomic factors. Examination of ORs across breastfeeding groups indicated the relationship between breastfeeding duration and dental caries to be non-linear-those with partial breast feeding for 3-5 months were the lowest risk group.

In table 4, we present results from two comparisons we made between never breast fed versus ever breast fed and between breast fed for less than 6 months versus breast fed for at least 6-7 months. We observed that ever breast fed was not associated with elevated risk except for at 30 months compared with never breast fed, whereas breast fed for at least 6-7 months was consistently associated with elevated risk of caries compared to breast fed for less than 6 months after adjusting for various biological and socioeconomic factors.

\section{DISCUSSION}

Using a large Japanese population-based longitudinal survey, we estimated the risk of early childhood dental caries between the ages of 30 and 66 months according to the duration of breast feeding during infants' first half year of life. We observed an elevated risk of dental caries at 30 months among those who were breast fed for at least 6-7 months, especially those who were exclusively breast fed. However, the adverse effect of breast feeding attenuated with continued follow-up. We did not find a dose-response relationship between breastfeeding duration in months and the risk of dental caries. 
Table 2 Proportion of children with dental caries by biological and socioeconomic factors at each survey from the third to the sixth $\left(\mathrm{n}_{\text {baseline }}=43383\right)$

\begin{tabular}{|c|c|c|c|c|c|}
\hline & & $\begin{array}{l}30 \text { Months } \\
(n=39404)(\%)\end{array}$ & $\begin{array}{l}42 \text { Months } \\
(\mathrm{n}=38 \text { 258) (\%) }\end{array}$ & $\begin{array}{l}54 \text { Months } \\
(\mathrm{n}=36673)(\%)\end{array}$ & $\begin{array}{l}66 \text { Months } \\
(n=35547)(\%)\end{array}$ \\
\hline \multicolumn{6}{|l|}{ Biological factors } \\
\hline \multicolumn{6}{|l|}{ Birth weight ${ }^{*}, g$} \\
\hline$<2500$ & $(n=2231)$ & $6 \dagger$ & 15 & 25 & 34 \\
\hline 2500-2999 & $(n=16159)$ & 7 & 18 & 26 & 36 \\
\hline $3000-3499$ & $(n=19411)$ & 7 & 18 & 28 & 37 \\
\hline$\geq 3500$ & $(n=5582)$ & 9 & 20 & 30 & 39 \\
\hline \multicolumn{6}{|l|}{ Sex } \\
\hline Female & $(n=21010)$ & 7 & 18 & 27 & 36 \\
\hline Male & $(n=22373)$ & 7 & 18 & 27 & 37 \\
\hline \multicolumn{6}{|l|}{ Parity } \\
\hline 1 & $(n=19875)$ & 6 & 15 & 24 & 33 \\
\hline 2 & $(n=14639)$ & 9 & 20 & 28 & 38 \\
\hline 3 & $(n=4729)$ & 10 & 23 & 35 & 45 \\
\hline$\geq 4$ & $(n=1000)$ & 11 & 23 & 34 & 45 \\
\hline \multicolumn{6}{|l|}{ Maternal age at delivery } \\
\hline$<25$ & $(\mathrm{n}=5861)$ & 8 & 20 & 30 & 40 \\
\hline 25-29.9 & $(n=16848)$ & 7 & 17 & 26 & 35 \\
\hline $30-34.9$ & $(n=15200)$ & 7 & 18 & 27 & 36 \\
\hline$\geq 35$ & $(n=5474)$ & 8 & 20 & 30 & 39 \\
\hline \multicolumn{6}{|l|}{ Socioeconomic factors } \\
\hline \multicolumn{6}{|l|}{ Maternal educational attainment } \\
\hline High school or less & $(n=18023)$ & 8 & 20 & 30 & 40 \\
\hline Two-year college or vocational school & $(n=16715)$ & 7 & 17 & 26 & 36 \\
\hline Four-year college or higher & $(n=5615)$ & 6 & 13 & 22 & 30 \\
\hline \multicolumn{6}{|l|}{ Maternal smoking status } \\
\hline Non-smoker & $(n=35623)$ & 7 & 18 & 26 & 36 \\
\hline Light smoker & $(n=4817)$ & 8 & 20 & 30 & 39 \\
\hline Heavy smoker & $(n=2622)$ & 9 & 22 & 32 & 44 \\
\hline \multicolumn{6}{|l|}{ Marital status } \\
\hline Married & $(n=42827)$ & 7 & 18 & 27 & 36 \\
\hline Not married & $(n=556)$ & 9 & 20 & 30 & 42 \\
\hline \multicolumn{6}{|l|}{ Region of birth } \\
\hline Hokkaido & $(n=1674)$ & 8 & 18 & 27 & 37 \\
\hline Tohoku & $(n=3244)$ & 9 & 21 & 32 & 41 \\
\hline Kanto & $(n=13828)$ & 7 & 16 & 24 & 33 \\
\hline Chubu & $(n=7874)$ & 7 & 18 & 28 & 37 \\
\hline Kinki & $(n=7935)$ & 7 & 18 & 27 & 37 \\
\hline Chugoku & $(n=2601)$ & 7 & 18 & 27 & 37 \\
\hline Shikoku & $(n=1276)$ & 7 & 20 & 29 & 40 \\
\hline Kyushu/Okinawa & $(n=4951)$ & 9 & 21 & 31 & 42 \\
\hline \multicolumn{6}{|l|}{ Family income* } \\
\hline$<250$ & $(n=3265)$ & $9 \dagger$ & 21 & 30 & 40 \\
\hline 250-499 & $(n=15256)$ & 8 & 19 & 29 & 38 \\
\hline $500-749$ & $(n=14235)$ & 7 & 18 & 27 & 36 \\
\hline$\geq 750$ & $(n=7860)$ & 6 & 15 & 24 & 33 \\
\hline
\end{tabular}

${ }^{\star}$ Treated as continuous in the statistical analyses.

†The percentage describes the proportion of children with dental caries (versus without) within each category in the left column at each age (eg, the proportion of children with dental caries in the $<2500 \mathrm{~g}$ category at 30 months).

\section{Comparison with other studies}

Most studies on the relationship between breast feeding and dental caries that we reviewed showed no effect of breast feeding on dental caries. ${ }^{16-20}$ However, a caveat about all the studies (including ours) is the lack of standardised assessment of breast feeding. For example, breastfeeding duration was not uniform across studies.
In a study by Kramer et $a l^{20}$ the comparison was between 3 months of exclusive breast feeding versus 6 months, whereas in a study by Nunes $e t a l,{ }^{18}$ the comparison was between less than 12 months of breast feeding versus more than 12 months. Iida $e t a l^{16}$ used several assessments of breast feeding including durations of full breast feeding and exclusive breast feeding and 
Table 3 Unadjusted and adjusted OR with $95 \% \mathrm{Cls}$ for associations between duration of breast feeding and dental caries between the ages of 30 and 66 months $\left(n_{\text {baseline }}=43113\right)$

\begin{tabular}{|c|c|c|}
\hline & $\begin{array}{l}\text { Unadjusted model } \\
\text { OR }(95 \% \mathrm{CI})\end{array}$ & $\begin{array}{l}\text { Adjusted model }{ }^{\star} \\
\text { OR }(95 \% \mathrm{Cl})\end{array}$ \\
\hline \multicolumn{3}{|l|}{ At 30 months $(n=39631)$} \\
\hline Exclusively formula fed $\left(n_{\text {case }}=140 / 2264: 6.2 \%\right)$ & 1.00 (reference) & 1.00 (reference) \\
\hline $1-2$ months breast feeding $\left(\mathrm{n}_{\text {case }}=449 / 7474: 6.0 \%\right)$ & $0.97(0.80$ to 1.18$)$ & $0.93(0.75$ to 1.15$)$ \\
\hline 3-5 months breast feeding ( $\left.n_{\text {case }}=413 / 7823: 5.3 \%\right)$ & 0.85 (0.69 to 1.03$)$ & $0.90(0.72$ to 1.11$)$ \\
\hline $6-7$ months breast feeding ( $n_{\text {case }}=971 / 13140: 7.4 \%$ ) & $1.21(1.01$ to 1.45$)$ & 1.39 (1.14 to 1.70$)$ \\
\hline Exclusively breast feeding $\left(\mathrm{n}_{\text {case }}=864 / 8930: 9.7 \%\right)$ & $1.63(1.35$ to 1.96$)$ & $1.78(1.45$ to 2.17$)$ \\
\hline \multicolumn{3}{|l|}{ At 42 months ( $n=38486)$} \\
\hline Exclusively formula fed $\left(n_{\text {case }}=399 / 2190: 18.2 \%\right)$ & 1.00 (reference) & 1.00 (reference) \\
\hline $1-2$ months breast feeding ( $\left.n_{\text {case }}=1230 / 7176: 17.1 \%\right)$ & $0.93(0.82$ to 1.05$)$ & $0.92(0.80$ to 1.05$)$ \\
\hline 3-5 months breast feeding ( $\left.n_{\text {case }}=1191 / 7547: 15.8 \%\right)$ & $0.84(0.74$ to 0.95$)$ & 0.90 (0.78 to 1.03$)$ \\
\hline $6-7$ months breast feeding $\left(n_{\text {case }}=2332 / 12852: 18.1 \%\right)$ & 1.00 (0.89 to 1.12$)$ & 1.13 (0.99 to 1.28$)$ \\
\hline Exclusively breast feeding $\left(n_{\text {case }}=1797 / 8721: 20.6 \%\right)$ & 1.17 (1.03 to 1.31$)$ & 1.26 (1.11 to 1.44$)$ \\
\hline \multicolumn{3}{|l|}{ At 54 months $(n=36881)$} \\
\hline Exclusively formula fed ( $\left.n_{\text {case }}=575 / 2066: 27.8 \%\right)$ & 1.00 (reference) & 1.00 (reference) \\
\hline $1-2$ months breast feeding ( $\left.n_{\text {case }}=1863 / 6810: 27.4 \%\right)$ & $0.98(0.88$ to 1.09$)$ & 0.96 (0.85 to 1.08$)$ \\
\hline 3-5 months breast feeding ( $\left.n_{\text {case }}=1809 / 7217: 25.1 \%\right)$ & 0.87 (0.78 to 0.97$)$ & 0.93 (0.83 to 1.05$)$ \\
\hline $6-7$ months breast feeding $\left(\mathrm{n}_{\text {case }}=3280 / 12381: 26.5 \%\right)$ & $0.94(0.84$ to 1.04$)$ & $1.03(0.92$ to 1.15$)$ \\
\hline Exclusively breast feeding ( $\left.n_{\text {case }}=2428 / 8407: 28.9 \%\right)$ & $1.05(0.95$ to 1.17$)$ & 1.10 (0.98 to 1.24$)$ \\
\hline \multicolumn{3}{|l|}{ At 66 months ( $\mathrm{n}=35754)$} \\
\hline Exclusively formula fed $\left(n_{\text {case }}=743 / 1985: 37.4 \%\right)$ & 1.00 (reference) & 1.00 (reference) \\
\hline $1-2$ months breast feeding $\left(n_{\text {case }}=2429 / 6542: 37.1 \%\right)$ & $0.99(0.89$ to 1.10$)$ & 1.00 (0.90 to 1.12$)$ \\
\hline $3-5$ months breast feeding ( $\left.n_{\text {case }}=2467 / 7008: 35.2 \%\right)$ & 0.91 (0.82 to 1.01$)$ & $0.98(0.88$ to 1.10$)$ \\
\hline $6-7$ months breast feeding $\left(n_{\text {case }}=4357 / 12053: 36.2 \%\right)$ & 0.95 (0.86 to 1.04$)$ & 1.07 (0.96 to 1.19$)$ \\
\hline Exclusively breast feeding $\left(n_{\text {case }}=3042 / 8166: 37.3 \%\right)$ & $0.99(0.90$ to 1.10$)$ & 1.06 (0.95 to 1.18$)$ \\
\hline
\end{tabular}

Table 4 Unadjusted and adjusted OR with $95 \%$ Cls for associations between breast feeding and dental caries between the ages of 30 and 66 months ( $n_{\text {baseline }}=43113$ )

$\begin{array}{ll}\text { Unadjusted model } & \text { Adjusted model } \\ \text { OR }(95 \% \mathrm{Cl}) & \text { OR }(95 \% \mathrm{Cl})\end{array}$

Never breast fed (reference) vs

At 30 months $(n=39631)$

Ever breast fed $1.18(0.99$ to 1.41$)$ $1.23(1.01$ to 1.48$)$

At 42 months ( $n=38$ 486)

Ever breast fed

At 54 months $(n=36881)$

Ever breast fed $0.96(0.87$ to 1.06$)$ 1.00 (0.90 to 1.12$)$

At 66 months ( $n=35547)$

Ever breast fed

Breast fed for less than 6 months (reference) vs

At 30 months ( $n=39631)$

Breast fed for at least 6-7 months $1.03(0.93$ to 1.14$)$

At 42 months ( $n=38$ 486)

Breast fed for at least 6-7 months $0.96(0.87$ to 1.05$)$

At 54 months $(n=36881)$

Breast fed for at least 6-7 months

At 66 months ( $n=35$ 547)

Breast fed for at least 6-7 months

1.50 (1.38 to 1.62$)$

$1.18(1.12$ to 1.25$)$

1.06 (1.01 to 1.11$)$

$1.01(0.97$ to 1.06$)$
$1.68(1.53$ to 1.83$)$

1.29 (1.21 to 1.36$)$

$1.11(1.06$ to 1.17$)$

$1.07(1.02$ to 1.12$)$

${ }^{*}$ Adjusted for birth weight, sex, parity, maternal age at delivery, maternal educational attainment, maternal smoking status, marital status at delivery, family, and region of birth and residence. 
found that history of breast feeding (never vs ever) was not associated with early childhood caries among children between the ages of 2 and 5, which seemed to be consistent with our findings presented in table 4 . A study by Chaffee $e t a l^{25}$ showed that breast feeding for up to 24 months was associated with elevated risk of dental caries at 38 months compared with breast feeding for less than 6 months, which corroborates our findings presented in table 4 .

Another issue may be the timing of outcome assessment. Ages of children vary from study to study (eg, 1842 months in Nunes' study to 6.5 years in Kramer's study). These variations in assessing breast feeding and dental caries complicate the comparison of studies and may explain the discrepancy between our study and previous studies which showed no effect of breast feeding.

\section{Plausible mechanism from breast feeding to dental caries}

An absence of a dose-response relationship between the duration of breast feeding and the risk of dental caries suggests that breast feeding for 6-7 months and possibly longer may increase the risk of dental caries due to concurrent events such as the early eruption of primary teeth starting around 6 months. ${ }^{9} 10$ Lower central incisors usually begin to erupt around 6 months followed by upper central incisors. These teeth would be present if mothers continue to breastfeed after 6 months and would most likely be affected by exposure to breast milk, especially if breast feeding is frequent. Thus, in future studies on breast feeding and early childhood caries, the timing (eg, at 6 months of age) and possibly the sequence of teeth eruption may be another factor to consider.

\section{Strengths}

One of the strengths of our study is the large sample size, which allowed us to estimate the risk of dental caries according to the duration of breast feeding. To the best of our knowledge, our study is the first population-based study to estimate the risk of dental caries according to breastfeeding duration on a continuum. Taking advantage of a longitudinal survey, we were also able to demonstrate changes in the risk of dental visits due to dental caries from the age of 2 to 5 .

Availability of rich information on biological and socioeconomic factors is another strength of our study. The effect of breastfeeding duration on dental caries seems to fade over early years, while the gradient in dental caries by biological and socioeconomic factors persists or even gains strength as shown in table 2. Reviews suggest that socioeconomic status is a strong determinant of dental caries. ${ }^{23}{ }^{26}$ Therefore, adjustment for maternal educational attainment, maternal smoking status, family income and other factors reduced threats to the validity of our findings.

\section{Limitations}

The duration of breast feeding in months between 0 and 7 was ascertained when an infant was at 6 or 7 months of age; therefore, the chance of recall bias seems unlikely. However, we could not ascertain the amount of time an infant was breast fed on each day. Since the amount of time teeth have been exposed to carbohydrates (ie, breast milk) is directly related to the development of dental caries, factors such as the frequency of breast feeding and patterns of night-time feeding may be the potential pathway linking breast feeding and dental caries. ${ }^{13} 14 \quad 252728$ An Australian survey indicated that mothers who exclusively breast fed their 6-month infants spent more time feeding than those who partially breast fed or exclusively formula fed. ${ }^{29}$ A US study on infant feeding practices demonstrated that mothers who breastfeed were much more likely to sleep by their infants for the facilitation of night-time feedings compared with those who formula feed (eg, $53 \%$ vs $7 \%$ at 6 months). ${ }^{30}$ Thus, further research with methods that precisely measure the amount of time spent on breast feeding may be necessary to elucidate the mechanism.

We also could not ascertain the duration of breast feeding beyond 7 months. Though we observed a higher risk of dental caries at 30 months and later among those who had been breast fed for at least 6-7 months compared with those who had been breast fed for less than 6 months, the relationship between breastfeeding duration beyond 7 months and the incidence of dental caries remains unknown in this study. A guideline on breast feeding and weaning disseminated by MHLW in 2007 recommended that weaning start at 5 or 6 months. ${ }^{31}$ A national survey on infant feeding and nutrition conducted in 2005 summarised that over $90 \%$ of families had begun weaning by 6 months. ${ }^{32}$ Therefore, the impact of breast feeding on dental caries should diminish beyond 6 months due to reduced or discontinued breast feeding in the Japanese population. Very early termination of breast feeding may have exposed infants to sugared beverages and foods sooner than those with a longer duration of breast feeding, which may explain the higher risk of dental caries in the exclusively formula fed group compared with the partially breast fed for 3-5 months group before controlling for biological and socioeconomic factors.

Among studies on breast feeding and dental caries, the use of decayed or filled primary tooth surfaces (dfs) was common. Since dfs were unavailable in the LSB21, we used dental visits reported by a caregiver as a proxy for the occurrence of dental caries. To assess the accuracy of this outcome, we obtained the nationwide prevalence of dental caries from a summary of oral health screening for 3-year-olds mandated by local governments. ${ }^{33}$ The national prevalence of dental caries was $30 \%$ with a compliance rate of $88 \%$ in 2004, whereas the proportion of children with dental caries was $27 \%$ at the fifth survey (ie, the proportion of children with a dental visit between 3 and 4 years of age) in the LSB21. Therefore, we may have slightly underestimated data on dental caries.

The impact of fluoride application at individual and collective levels is likely to be minor. Few local 
governments have enacted fluoridation of drinking water in Japan, and about $80 \%$ of commercial toothpaste products available on the Japanese market in 2003 already contained some amount of fluoride. ${ }^{34}$ An ecological study using a municipal-level prevalence of dental caries among 3-year-olds in 2000 showed that topical fluoride application explained only $0.8 \%$ of the total variation in the outcome. ${ }^{35}$

Other weaknesses include residual and unmeasured confounding. For example, a lack of access to oral healthcare services for socially disadvantaged families may be an issue. Given that more educated mothers have better access to dental visits, we attempted to circumvent the chance of confounding by including various socioeconomic factors in the model. Financial support from the central and local governments should also decrease the social gradient in utilisation of oral healthcare services for young children. However, unmeasured confounding such as parents' compliance with health-related guidelines-including willingness to seek preventive dental care for a young child-may also be associated with adherence to the official guidelines for exclusive breast feeding up to 6 months and thus potentially bias the estimates away from the null even after controlling for various socioeconomic factors.

\section{CONCLUSION}

We found an association between breast feeding for at least 6 or 7 months and elevated risk of dental caries during the early years of life. Our findings align with the recommendations of American and Japanese paediatric dentistry organisations that breastfeeding mothers need to be careful with their infants' oral hygiene after 6 months of age. Although our study adds to the body of knowledge, further studies with more elaborate methods of assessment of breast feeding may be necessary to determine the cariogenic nature of breast feeding. In the meantime, given the many benefits of breast feeding, the practice should continue to be strongly encouraged.

\section{Author affiliations}

${ }^{1}$ Department of Public Health and Health Policy, Institute of Biomedical Sciences, Hiroshima University, Hiroshima, Japan

${ }^{2}$ Department of Human Ecology, Okayama University Graduate School of Environmental and Life Science, Okayama, Japan

${ }^{3}$ Center for Regional Research, Okayama University, Okayama, Japan

${ }^{4}$ Department of Nursing, Okayama Prefectural University Graduate School of Health and Welfare Science, Okayama, Japan

${ }^{5}$ Department of Epidemiology, Okayama University Graduate School of Medicine, Dentistry and Pharmaceutical Sciences, Okayama, Japan

${ }^{6}$ Department of Social and Behavioral Sciences, Harvard School of Public Health, Boston, Massachusetts, USA

Contributors TK designed the study, drafted the initial manuscript and approved the final manuscript as submitted. TY contributed to the acquisition and interpretation of data, critically reviewed and revised the manuscript for important intellectual content and approved the final manuscript as submitted MY contributed to the analysis of the data, critically reviewed and revised the manuscript for important intellectual content and approved the final manuscript as submitted. SI obtained the data set from the Japanese Ministry of Health, critically revised the manuscript for important intellectual content and approved the final manuscript as submitted. KS contributed to the interpretation of data, critically revised the manuscript for important intellectual content and approved the final manuscript as submitted. HD conceptualised the study, negotiated with the Ministry of Health to obtain the data, critically revised the manuscript for important intellectual content and approved the final manuscript as submitted. IK supervised the analyses and the writing of the manuscript, critically revised the manuscript for important intellectual content and approved the final manuscript as submitted.

Funding This work was supported in part by the Health and Labour Sciences Research Grants on Health Research on Children, Youth and Families (grant no: H24-Jisedai-Ippan-004) as well as the Grant for Environmental Research Projects from the Sumitomo Foundation.

\section{Competing interests None.}

Ethics approval The Okayama University Graduate School of Medicine, Dentistry and Pharmaceutical Sciences Institutional Review Board (No. 486)

Provenance and peer review Not commissioned; externally peer reviewed.

Data sharing statement No additional data are available.

Open Access This is an Open Access article distributed in accordance with the Creative Commons Attribution Non Commercial (CC BY-NC 4.0) license, which permits others to distribute, remix, adapt, build upon this work noncommercially, and license their derivative works on different terms, provided the original work is properly cited and the use is non-commercial. See: http:// creativecommons.org/licenses/by-nc/4.0/

\section{REFERENCES}

1. Health Labour and Welfare Statistic Association. Journal of health and welfare statistics [Kokumin Eisei no Doukou]. Tokyo: Health Labour and Welfare Statistic Association, 2014; Contract No.: 9.

2. National Center for Health Statistics. Health, United States, 2012 with special feature on emergency care. Hyattsville, MD: National Center for Health Statistics, 2013.

3. Casamassimo PS. Pediatric dentistry: infancy through adolescence. St. Louis, MO: Elsevier/Saunders, 2013.

4. World Health Organization. Exclusive Breastfeeding Geneva (cited $14 \mathrm{Jul}$ 2013). http://www.who.int/nutrition/topics/exclusive breastfeeding/en/

5. American Academy of Pediatrics. Breastfeeding and the use of human milk. Pediatrics 2012;129:e827-41.

6. A Committee on Promoting Breastfeeding. Pediatricians and promoting breastfeeding (in Japanese). J Jpn Pediatr Soc 2011;115:1363-89.

7. Bowen WH, Lawrence RA. Comparison of the cariogenicity of cola, honey, cow milk, human milk, and sucrose. Pediatrics 2005;116:921-6.

8. Peres RC, Coppi LC, Volpato MC, et al. Cariogenic potential of cows', human and infant formula milks and effect of fluoride supplementation. Br J Nutr 2009;101:376-82.

9. American Academy on Pediatric Dentistry Council on Clinical Affairs. Policy on dietary recommendations for infants, children, and adolescents. Pediatr Dent 2008:30(7 Suppl):47-8.

10. Japanese Society of Pediatric Dentistry. Recommendations (in Japanese). Tokyo, 2011 (cited 10 Jul 2013). http://www.jspd.or. jp/contents/main/proposal/index03 03.html

11. Valaitis R, Hesch R, Passarelli $C$, et al. A systematic review of the relationship between breastfeeding and early childhood caries. Can J Public Health 2000;91:411-17.

12. Ribeiro NM, Ribeiro MA. Breastfeeding and early childhood caries: a critical review. J Pediatr (Rio J) 2004;80(5 Suppl):S199-210.

13. Feldens CA, Giugliani ERJ, Vigo A, et al. Early feeding practices and severe early childhood caries in four-year-old children from Southern Brazil: a birth cohort study. Caries Res 2010;44:445-52.

14. Sayegh A, Dini EL, Holt RD, et al. Oral health, sociodemographic factors, dietary and oral hygiene practices in Jordanian children. J Dent 2005;33:379-88.

15. Al-Malik MI, Holt RD, Bedi R. Prevalence and patterns of caries, rampant caries, and oral health in two- to five-year-old children in Saudi Arabia. J Dent Child 2003;70:235-42.

16. lida $\mathrm{H}$, Auinger $\mathrm{P}$, Billings RJ, et al. Association between infant breastfeeding and early childhood caries in the United States. Pediatrics 2007;120:e944-52. 
17. Rosenblatt A, Zarzar P. Breast-feeding and early childhood caries: an assessment among Brazilian infants. Int J Paediatr Dent 2004;14:439-45.

18. Nunes AM, Alves CM, Borba de Araujo F, et al. Association between prolonged breast-feeding and early childhood caries: a hierarchical approach. Community Dent Oral Epidemiol 2012;40:542-9.

19. Dye BA, Shenkin JD, Ogden CL, et al. The relationship between healthful eating practices and dental caries in children aged $2-5$ years in the United States, 1988-1994. J Am Dent Assoc 2004;135:55-66.

20. Kramer MS, Matush L, Bogdanovich N, et al. Health and development outcomes in 6.5-y-old children breastfed exclusively for 3 or 6 mo. Am J Clin Nutr 2009;90:1070-4.

21. Ministry of Health Labour and Welfare. Longitudinal Survey of Babies in 21st Century (cited 20 Mar 2012). http://www.mhlw.go.jp/ english/database/db-hw/babies02/index.html

22. Kim Seow W. Environmental, maternal, and child factors which contribute to early childhood caries: a unifying conceptual model. Int J Paediatr Dent 2012;22:157-68.

23. Reisine ST, Psoter W. Socioeconomic status and selected behavioral determinants as risk factors for dental caries. J Dent Educ 2001;65:1009-16.

24. Japan Society for Oral Health. Statistics of oral health [Sika eisei no doukou]. Tokyo: Ishiyaku Shuppan Kai, 2007.

25. Chaffee BW, Feldens CA, Vitolo MR. Association of long-duration breastfeeding and dental caries estimated with marginal structural models. Ann Epidemiol 2014;24:448-54.

26. Fisher-Owens SA, Gansky SA, Platt LJ, et al. Influences on children's oral health: a conceptual model. Pediatrics 2007;120: e510-20.
27. Helderman WV, Soe W, van't Hof MA. Risk factors of early childhood caries in a southeast Asian population. $J$ Dent Res 2006;85:85-8.

28. Thitasomakul S, Piwat S, Thearmontree A, et al. Risks for early childhood caries analyzed by negative binomial models. J Dent Res 2009;88:137-41.

29. Smith JP, Forrester R. Who pays for the health benefits of exclusive breastfeeding? An analysis of maternal time costs. J Hum Lact 2013;29:547-55.

30. Hauck FR, Signore C, Fein SB, et al. Infant sleeping arrangements and practices during the first year of life. Pediatrics 2008;122(Suppl 2): S113-20.

31. Ministry of Health Labour and Welfare. Guideline on infant feeding and weaning [in Japanese]. Tokyo: Ministry of Health Labour and Welfare, 2007 (cited 7 Oct 2014). http://www.mhlw.go.jp/shingi/2007/ 03/dl/s0314-17.pdf

32. Ministry of Health Labour and Welfare. Summary of 2005 Survey of Dental Diseases [in Japanese]. 2007; 6 Oct 2014. http://www.mhlw. go.jp/topics/2007/01/tp0129-1.html

33. National Institute of Public Health. Oral health check-up for three-year-old infants [Nyuyouji Sika Kensin]. Wako, Saitama: National Institute of Public Health, 2004.

34. The Lion Foundation for Dental Health. Information on Fluoride [in Japanese] (cited 6 Oct 2014). https://www.lion-dent-health.or.jp/ basic/basic14.htm

35. Aida J, Ando Y, Aoyama $\mathrm{H}$, et al. An ecological study on the association of public dental health activities and sociodemographic characteristics with caries prevalence in Japanese 3-year-old children. Caries Res 2006;40:466-72. 